\title{
Respiratory Effects of Division of the Carotid Sinus Nerve in the Lamb Soon After the Initiation of Breathing
}

\author{
H.S. Harned, Jr. ${ }^{[16]}$, R.T. Herrington, C.A. Griffin, III, W.S. Berrymilt, Jr. and \\ L. G. MAGKINNEY \\ Department of Pediatrics, University of North Carolina School of Medicine, \\ Chapel Hill, North Carolina, USA
}

\section{Extract}

Increased activity of the carotid chemoreceptors from hypoxia and hypercarbia, induced by occlusion of the umbilical cord, has importance in initiating effective respiration of the term lamb. The state of hypoxia and hypercarbia continuing after birth should also evoke strong stimulation from the carotid glomi. The present experiments measure the effects on ventilation resulting from interruption of carotid chemoreceptor stimulation to the respiratory center by division of each carotid sinus nerve of the lamb during the newborn period.

Ewes were given spinal anesthesia and each lamb was partly removed from the uterus to permit an operative approach through the neck. The carotid sinus nerves were exposed and tagged with loose threads to facilitate division of the nerve at a later stage. The lamb was then delivered, its umbilical cord clamped, and its inspiratory volume measured by pneumotachometric techniques.

Each of the seven lambs studied was permitted to establish respiration before its first carotid sinus nerve was divided. The time intervals between birth and division of the first nerves varied from 5.5 to 38.5 minutes after birth. The second nerves were divided several minutes later when respiration had recovered from the effects of division of the first nerve. A significant fall in ventilation was observed within 50 seconds after division of each carotid sinus nerve. Improved ventilation began to occur in some animals 150 seconds later, and occurred in all animals within several minutes after division of each nerve. Levels of $\mathrm{PO}_{2}, \mathrm{pH}$ and $\mathrm{PCO}_{2}$ in carotid artery blood before nerve division revealed hypoxia, hypercarbia and acidosis; this aberrant state became worse during the period of diminished ventilation. The minimal changes in heart rate and blood pressure resulting from interruption of baroreceptor fibers were insufficient to influence respiration.

\section{Speculation}

When viewed in conjunction with experiments performed in lambs immediately at birth and with those performed in older newborn lambs, these experiments reveal a continuum of physiologic activity of the carotid chemoreceptors which is important in the establishment and regulation of breathing. The consistent recovery of ventilation after the initial depression produced by division of the second carotid sinus nerve indicates that under these conditions, chemical regulatory mechanisms other than those of the carotid glomi are important in the lamb. The only peripheral chemoreceptors known to be active in the newborn are those in the carotid bodies. Accordingly, some central chemosensor mechanisms must be invoked to explain the recovery of respiration. 


\section{Introduction}

With birth, there is in the fetus a depression in the concentrations of $\mathrm{Pa}_{2}$, a rise in $\mathrm{PaCO}_{2}$, and an increase in arterial $\mathrm{pH}$. These chemical changes may play a significant role in initiating respiration. Recent experiments have indicated that the carotid chemoreceptors are activated following occlusion of the umbilical cord of the term lamb delivered by hysterotomy $[7,8,13]$ and are important in initiating the effective respiratory efforts needed for survival [6].

The present experiments were designed to measure changes in ventilation resulting from division of the carotid sinus nerves of the newly born lamb several minutes after respiration had become established in order to evaluate the significance of chemoreceptor activity at this critical time.

\section{Methods and Materials}

Seven lambs at term were delivered by hysterotomy from ewes given spinal anesthesia by methods previously described $[6,8]$. The fetal head was delivered through a small incision in the uterine wall and was capped with a water-filled rubber glove to prevent ventilation. The skin of the anterior midline region of the neck was infiltrated with 4 to $5 \mathrm{ml}$ of $1 \%$ Lidocaine without epinephrine. The trachea was exposed and intubated. A short length of plastic tubing was attached to the tracheostomy tube and clamped to prevent ventilation. The rubber cap was removed from the head and the incision extended. The lingual artery on one side was catheterized, and the catheter tip was passed into the common carotid artery about one centimeter caudal to the carotid sinus. The carotid sinus nerves were then exposed bilaterally, and threads were looped loosely around each confluent carotid sinus and glossopharnygeal nerve close to the jugular foramen. During these procedures, each lamb was maintained within the uterus except for the head and neck.

The lamb was then removed from the uterus and allowed to lie at its mother's side. Carotid arterial blood pressure was recorded by a Statham P23 Db strain gauge connected to a carrier preamplifier in a Sanborn $550 \mathrm{M}$ recording system. The clamp was then removed from the plastic tracheal tube, and the tube was connected to a nonrebreathing valve assembly attached to a small Fleisch pneumotachograph. The pneumotachograph was attached to a Sanborn 270 pressure transducer which was connected to a second carrier preamplifier. The preamplifier output, which represented inspiratory flow, $\mathrm{dV} / \mathrm{d} t$, was fed into a Philbrick operational amplifier connected as an integrator with

18 Pediat. Res., Vol. 2, No. 4 (1968) a two-second time constant. A microswitch connected across the integrating capacitor was activated by a cam on a 3.6 RPM motor to give periods with a duration of $16^{2} / 3$ seconds. After further amplification, the integrator output was displayed and recorded photographically in the Samborn 550M system.

The use of the valve assembly between the pneumotachograph and the animal made it simple to identify the earliest respiratory efforts without the danger of clogging the pneumotachograph screen with tracheal fluids. In addition, since only inspired air passed through the pneumotachograph, no heating was necessary to prevent condensation.

None of the lambs showed consistent respiratory efforts prior to cord occlusion. They initiated and sustained breathing after the cord was deliberately clamped in a manner similar to that observed in a series of sham-operated animals [6]. At representative but arbitrary times after occlusion of the umbilical cord, and when respiration had become consistent, the first nerve was divided. The second nerve was divided when the animal had improved ventilation to a reasonably steady state.

Nerve division was accomplished by tying the threads around the confluent carotid sinus and glossopharyngeal nerves and immediately applying sufficient traction to divide the nerves between the tie and medulla. After these experiments were completed, the animals were sacrificed. Inspection revealed that the carotid sinus nerve had been divided successfully in each animal in this series.

The experimental procedures were attempted in four additional animals, three of which required resuscitative measures to establish rhythmic respirations. Although division of the carotid sinus nerves of these three animals produced results similar to those to be described, they were deleted from the study. The fourth animal, in which one carotid sinus nerve was found to be intact at postmortem examination, showed no change in ventilation after the 'mock' procedure when the nerve was left intact. This animal was also deleted from the study.

\section{Results}

The ventilatory patterns observed before and after division of the first carotid sinus nerves are shown in figures 1 through 3 . The inspiratory volumes are plotted against time after cord occlusion. Obvious decreases in ventilation during these intervals occurred after nerve division in animals $1,4,5,6$ and 7 . In the case of lamb 2 (fig. 1) and lamb 3 (fig. 2), the progressive rise in ventilation was arrested and each appeared to show a slight fall in ventilation soon after nerve division. 


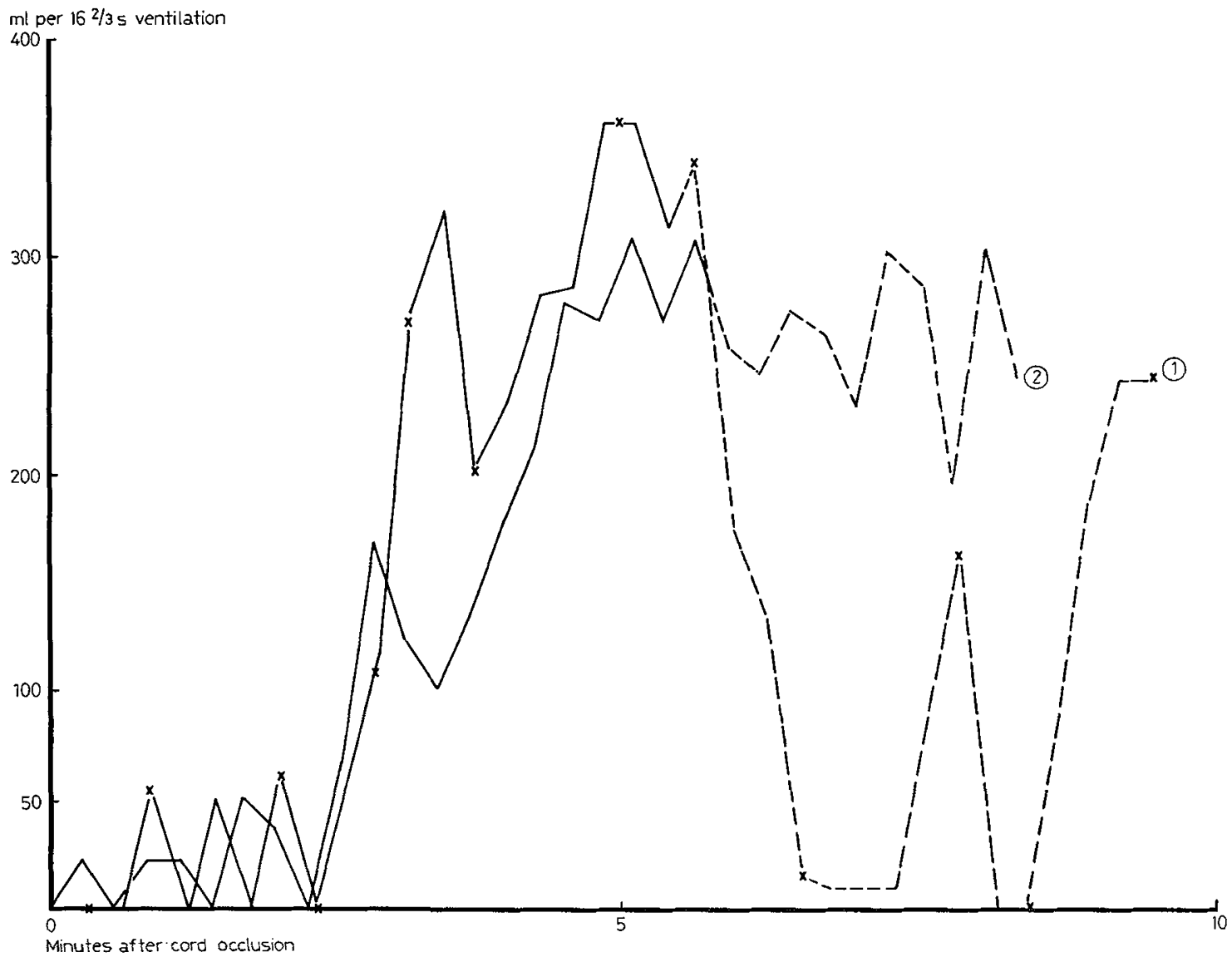

Fig. 1. Ventilation in $\mathrm{ml}$ of lambs 1 and 2 are plotted for each time interval $\left(16^{2} / 3\right.$ seconds) after occlusion of the umbilical cord. Solid lines represent ventilation before division of the first carotid sinus nerves; broken lines represent ventilation after first nerve division, performed 5.5 minutes after cord occlusion in lamb 1 and 5.8 minutes after cord occlusion in lamb 2.

The effects of the division of the first and then the second nerves are shown in figures 4 and 5. Baseline ventilation for each animal was derived by averaging values recorded in the four to six time intervals immediately preceding nerve division, with the exception of lamb 7 for which only two such intervals were averaged; this ventilation was considered as unity. The ratio of ventilation after nerve division to the baseline ventilation of each animal $(\mathrm{Vp} / \mathrm{Va})$ and the time intervals are delineated. A ratio of 1 would indicate that ventilation was continuing at baseline level. For each of the time intervals from $16^{2} / 3$ seconds to $83^{1} / 3$ seconds after the initial nerve division and for each of the intervals from $33^{1} / 3$ to $83^{1} / 3$ seconds after the second nerve division, each lamb showed a ventilatory volume below baseline. The probability that these events would occur independent of nerve division is less than 0.016 for each interval (Wilcoxon signed rank test [5]). Additionally, only 4 of 68 ventilation ratios exceeded unity after the first nerve was divided and only 3 of 64 ventilation ratios exceeded unity after division of the second nerve during the total periods shown in figures 4 and 5 . Comparisons made to an assumed steady ventilatory rate demonstrate a significant decrease in ventilation associated with nerve division. As the ventilation of several of these animals was still increasing at the time of nerve division, the probability figures may underestimate the significance of the effects produced.

The decrease in ventilation was associated in most instances with slowing of the respiratory rate rather than with decreased tidal volume. Changes in tidal volume were inconsistent; some of the animals which showed marked decreases in total ventilation per unit time resorted to infrequent gasps with large tidal volumes.

It is apparent that a few lambs began to show re- 


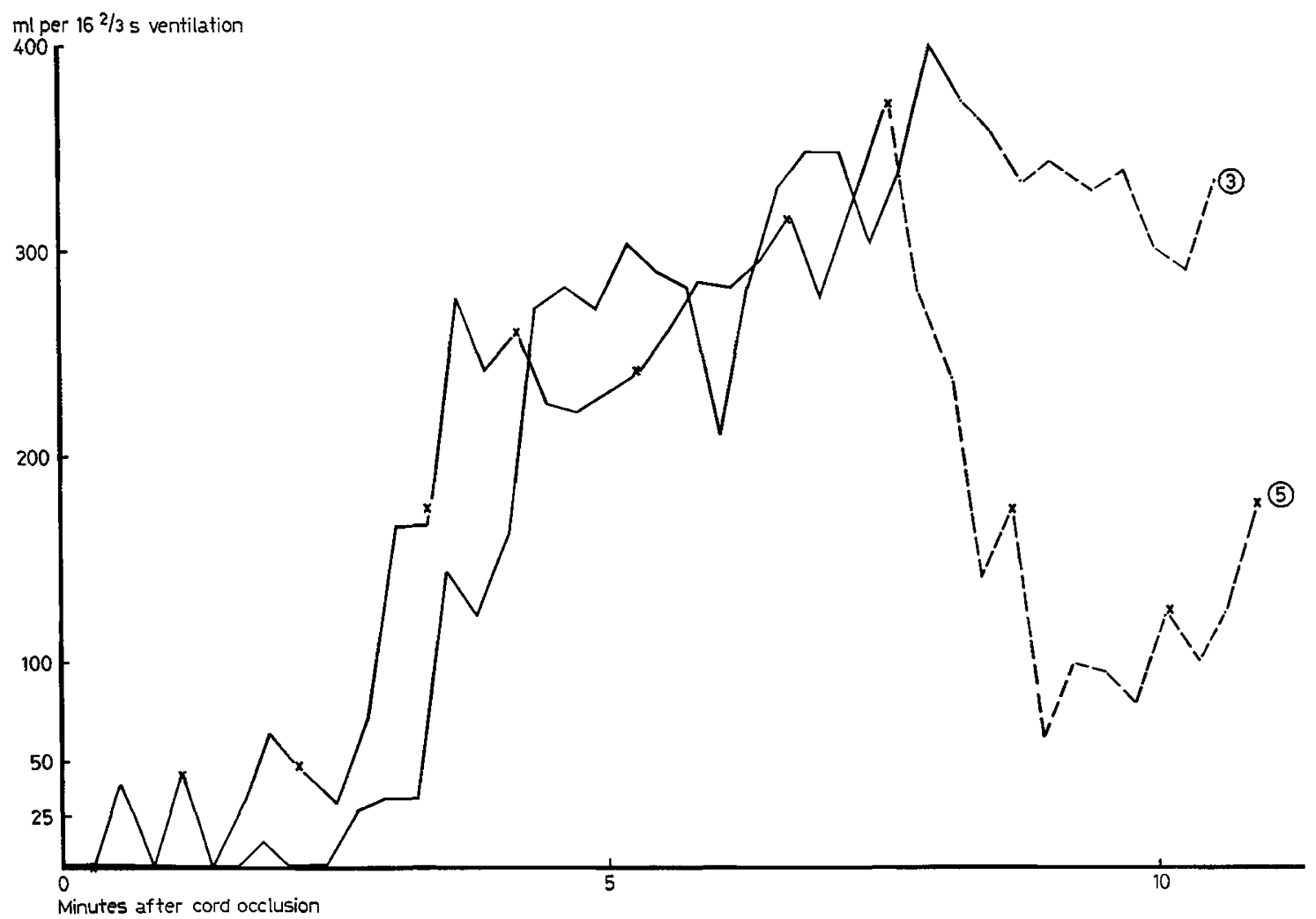

Fig.2. Ventilation of lambs 3 and 5 displayed as in figure 1. The first carotid sinus nerve of lamb 3 was divided 8.3 minutes after cord occlusion; the first nerve of lamb 5 was divided 8 minutes after cord occlusion.

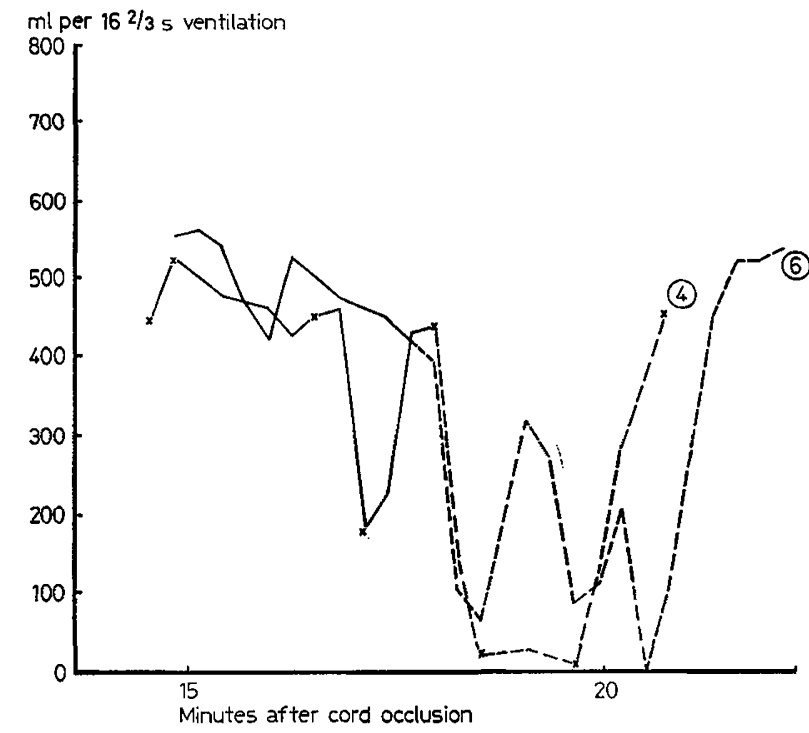

Fig. 3. Ventilation of lambs 4, 6 and 7 are plotted on a time base indicating minutes after cord occlusion. The first nerve divisions were made at 19, 18.4 and 38.5 minutes, respectively, in these three lambs.

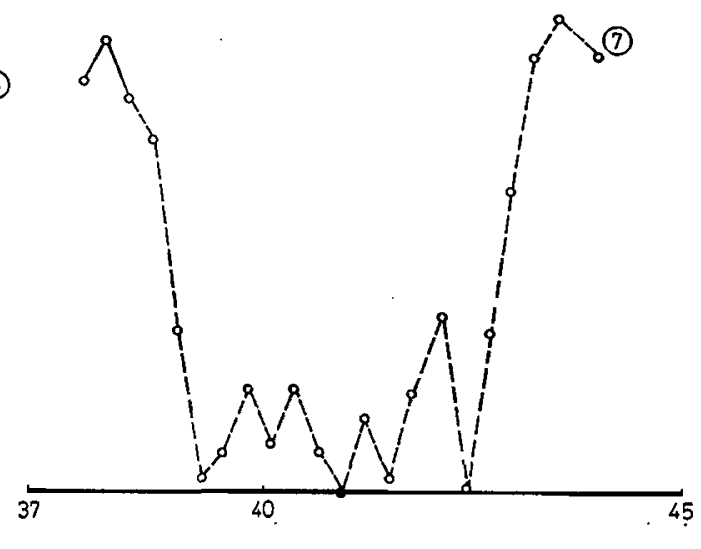




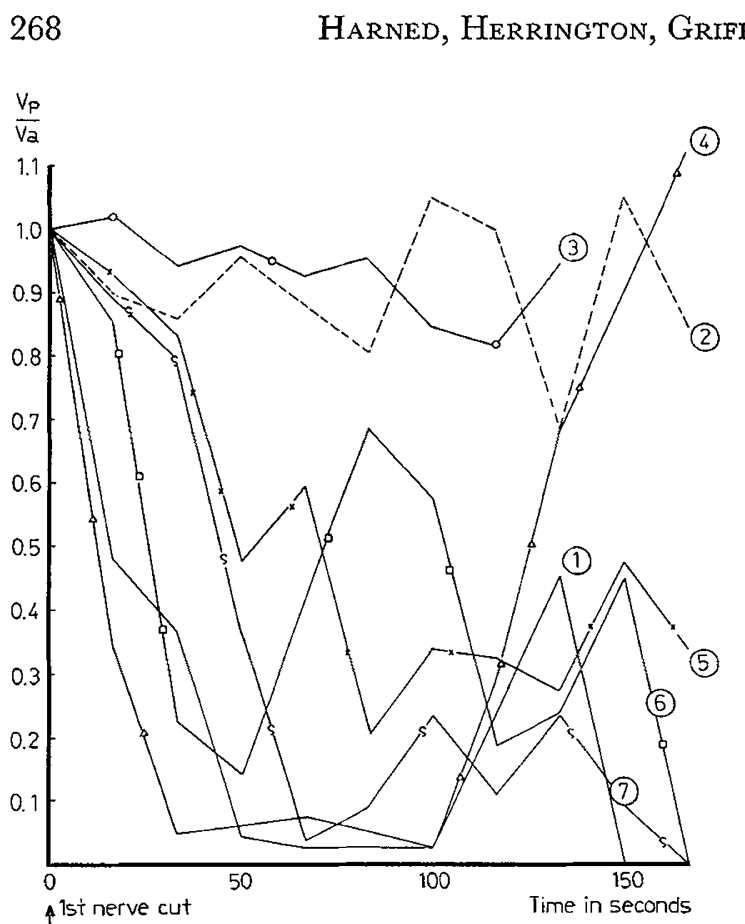

Fig.4. Ventilatory patterns after nerve division of the first carotid sinus nerve in seven lambs. Baseline ventilation (Va) and ventilation after nerve division ( $\mathrm{Vp}$ ) are expressed as a ratio $(\mathrm{Vp} / \mathrm{Va})$; this should be 1.0 were no effect produced by division of the nerves and if ventilation had continued at a steady level.

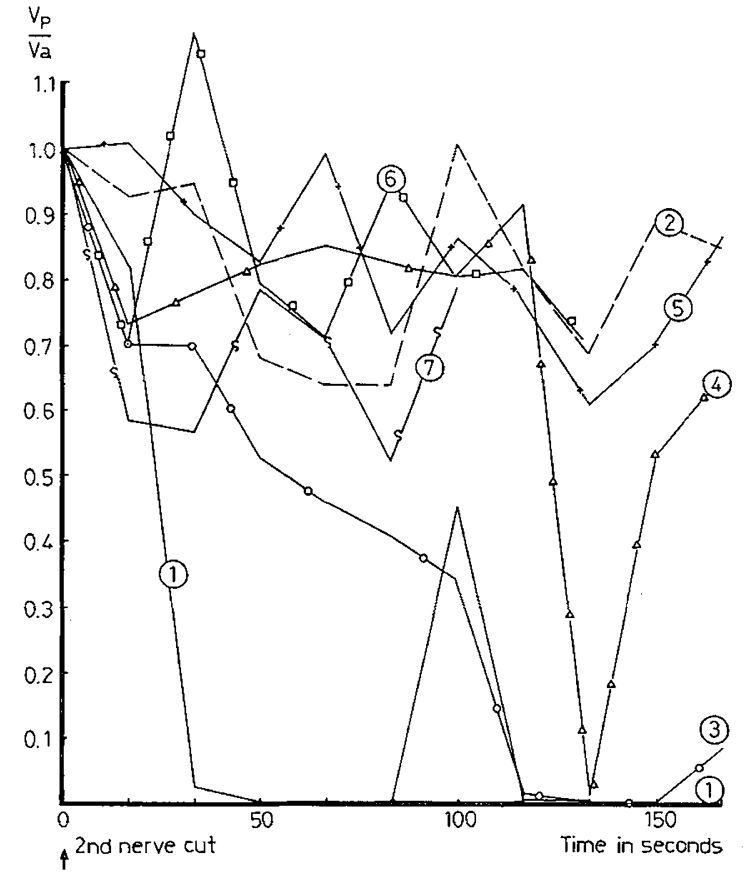

Fig.5. Ventilatory patterns after division of the second carotid sinus nerve in the seven lambs. $\mathrm{Vp} / \mathrm{Va}$ ratio and time are indicated as in figure 4.

Table I. Experimental data

\begin{tabular}{|c|c|c|c|c|c|c|c|c|c|c|c|c|}
\hline \multirow{2}{*}{$\begin{array}{l}\text { Experi- } \\
\text { ment } \\
\text { number }\end{array}$} & \multirow{2}{*}{$\begin{array}{l}\text { Nerve divided } \\
\text { (minutes after } \\
\text { cord } \\
\text { occlusion) }\end{array}$} & \multirow{2}{*}{$\begin{array}{l}\text { Baseline } \\
\text { ventilation } \\
\text { Average } \mathrm{ml} / \\
16^{2} / 3 \text { seconds }\end{array}$} & \multicolumn{10}{|c|}{$\begin{array}{l}\text { Ventilation after nerve division for each successive interval } \\
\qquad \text { of } 16^{2} / 3 \text { seconds }\end{array}$} \\
\hline & & & 1 & 2 & 3 & 4 & 5 & 6 & 7 & 8 & 9 & 10 \\
\hline \multirow[t]{2}{*}{1} & $\mathrm{R}-5.5$ & 355 & 170 & 130 & 15 & 10 & 10 & 10 & 80 & 160 & 0 & 0 \\
\hline & $\mathrm{L}-12$ & 189 & 155 & 5 & 0 & 0 & 0 & 160 & 0 & 0 & 0 & 0 \\
\hline \multirow[t]{2}{*}{2} & $\mathrm{R}-5.8$ & 285 & 255 & 244 & 272 & 261 & 228 & 300 & 283 & 194 & 300 & 240 \\
\hline & $L-8.5$ & 269 & 250 & 255 & 183 & 172 & 172 & 271 & 220 & 184 & 239 & 228 \\
\hline \multirow[t]{2}{*}{3} & L- 8.3 & 353 & 360 & 333 & 344 & 328 & 338 & 300 & 289 & 333 & - & - \\
\hline & $\mathrm{R}-10.6$ & 326 & 228 & 228 & 172 & 150 & 133 & 111 & 5 & 0 & 0 & 28 \\
\hline \multirow[t]{2}{*}{4} & $\mathrm{~L}-19.0$ & 408 & 140 & 20 & 25 & 30 & 20 & 10 & 115 & 278 & 367 & 455 \\
\hline & $\mathrm{R}-23.2$ & 547 & 400 & 425 & 450 & 465 & 450 & 440 & 500 & 7 & 290 & 355 \\
\hline \multirow[t]{2}{*}{5} & $L-8$ & 296 & 275 & 245 & 140 & 175 & 60 & 100 & 95 & 80 & 125 & 100 \\
\hline & $\mathrm{R}-19.4$ & 272 & 275 & 250 & 225 & 270 & 195 & 235 & 210 & 165 & 190 & 235 \\
\hline \multirow[t]{2}{*}{6} & $\mathrm{~L}-18.4$ & 462 & 395 & 105 & 65 & 195 & 315 & 265 & 85 & 110 & 205 & 0 \\
\hline & $\mathrm{R}-25.6$ & 542 & 380 & 635 & 430 & 385 & 515 & 435 & 440 & 375 & - & - \\
\hline \multirow[t]{2}{*}{7} & $\mathrm{~L}-38.5$ & 562 & 500 & 445 & 205 & 20 & 50 & 130 & 60 & 130 & 50 & 0 \\
\hline & $\mathrm{R}-42$ & 529 & 310 & 300 & 415 & 375 & 275 & 415 & - & - & - & - \\
\hline
\end{tabular}

The time of division of the first nerve after cord occlusion, the average baseline ventilation, and the ventilation noted for each successive time interval $(162 / 3$ seconds) after nerve division for each experiment are listed in the top row. The same parameters for the second nerve division of each experiment are listed in the second row. Division of the right carotid sinus nerve is designated by $R$ and the left by $L$. 
covery of ventilation even during the first 150 seconds following nerve division (figs. 4 and 5). Comparison of baseline ventilation before the first and the second nerve divisions (table I) reveals that six of the seven lambs returned to a level of ventilation $90 \%$ or more above that present before the initial nerve had been divided. One lamb even returned from a state of severely depressed ventilation to a level of $55 \%$ of its initial baseline. Periodic observations of the lambs following division of the second nerve revealed a similar pattern of ventilatory recovery. Five of the animals (Nos. 2,3,4,6, and 7) reached ventilatory levels equal to or slightly above those present preceding division of the second nerve. Lamb 5 was ventilating at a level slightly above $86 \%$ of its baseline when measurements were discontinued $31 / 2$ minutes after nerve division. Lamb 1 recovered ventilation, but quantitative tachometric measurements were not made.

Samples of blood from the carotid artery, obtained before the nerves were divided, revealed $\mathrm{P}_{2}$ values varying from 15.3 to $36.8 \mathrm{~mm} \mathrm{Hg}, \mathrm{pH}$ values varying from 6.92 to 7.15 , and $\mathrm{P}_{\mathrm{CO}_{2}}$ values varying from 43.4 to $83.1 \mathrm{~mm} \mathrm{Hg}$. These indicate that despite vigorous ventilation, the lambs had not recovered from the hypoxia and respiratory and metabolic acidosis associated with delivery by these methods. The decrease in ventilation after division of the carotid sinus nerve appeared to be influenced neither by the prior level of $\mathrm{PaO}_{2}$, nor by the degree of acidosis and hypercarbia.

Comparison of blood samples obtained from the carotid artery immediately before and 1-1.5 minutes after nerve division revealed an average drop in levels of $\mathrm{Pa}_{2}$ of $6.9 \mathrm{~mm} \mathrm{Hg}$, a rise in levels of $\mathrm{PaCO}_{2}$ of 7.1 $\mathrm{mm} \mathrm{Hg}$, and a decrease of $0.017 \mathrm{pH}$ units. Measurements of this sort were made in six experiments; all but one experiment showed changes of these three parameters in the direction expected. The lambs showing the most severe decrease in ventilation (experiments 1 , 3 , right nerve; and 4, left nerve) showed the most pronounced chemical changes.

Division of the left carotid sinus nerve was usually associated with a greater decrease in ventilation than division of the right nerve. The validity of this observation requires further study. Occasionally, there was considerable disparity in the size of the nerves on each side. Other marked anatomical differences were noted in the relation of the carotid sinus nerve to the glossopharyngeal nerve and in its pathway toward the carotid body.

No significant changes were observed in the heart rate of the lambs before and after division of their carotid sinus nerves. Several animals developed increases in systolic blood pressure of 5 to $10 \mathrm{~mm} \mathrm{Hg}$, but this was less striking than has been observed after carotid nerve division of older lambs.

\section{Discussion}

These experiments demonstrate that division of each carotid sinus nerve in the newborn lamb soon after respiration is initiated results in a rapid decrease in ventilation. Recovery from this effect occurs, however, within several minutes. This recovery might be explained by the ability of the arterial hypoxia, acidity, and hypercarbia, induced by the decreased ventilation, to increase activity of the remaining peripheral and central chemoreceptors.

Peripheral chemoreceptors other than the carotid glomi have not been shown to be of importance in the young lamb $[6,11,12]$. Recovery of ventilation after division of the first carotid sinus nerve, therefore, must be attributed to increased activity of the contralateral carotid body and of central chemosensing mechanisms. The recovery of ventilation after division of the second carotid sinus nerve must be attributed primarily to stimulation of central chemosensing mechanisms.

The changes in respiration documented in these experiments can be attributed only to the effects of severing fibers from carotid chemoreceptors. In addition to chemoreceptor fibers, baroreceptor fibers were divided, as were some postganglionic sympathetic and pressure receptor fibers, the functions of which have not been clearly defined [2]. Although baroreceptor potentials are very active in the carotid sinus nerve of the newborn lamb [8], severance of this nerve produced no significant change in heart rate; the inconsistent and slight increase in blood pressure recorded would not be expected to produce reflex effects on breathing.

The results of these experiments should be considered in relation to previous studies of carotid chemoreceptor function. Tonic chemoreceptor activity has been difficult to demonstrate in the fetus, but several investigators have proposed that even before birth the carotid body is functional $[3,4,8,13]$. In contrast, a striking increase in chemoreceptor activity has been recorded from the carotid sinus nerve of the lamb delivered by hysterotomy at the time when the umbilical cord was clamped [7, 8, 13]. This disparity might be explained by potentiation of chemoreceptor activity by the rapid rate of chemical change after cord occlusion [1] or by a critical diminution in blood flow through the carotid glomus. The latter would result in a marked decrease in glomic cellular oxygenation and an increase in local $\mathrm{pH}$ and hypercarbia. Although this local decrease in glomic blood flow has not been demonstrated, it might occur as a consequence of a decrease in blood flow in the carotid artery immediately after cord occlusion or as a result of increased sympathetic activity known to precede the increase in carotid chemoreceptor activity following cord occlusion [13]. Activation of the carotid chemoreceptors is important in the ini- 
tiation of effective breathing. This has been demonstrated in the unanesthetized term lamb delivered by hysterotomy by contrasting the intial breathing patterns of a group of animals in which both carotid sinus nerves were divided with a group subjected to mock operation in which these nerves were left intact [6]. Animals without carotid glomic activity experienced a striking depression of respiration which seriously compromised chance for survival. The present experiments revealed a less severe respiratory depression at the time the lamb developed effective breathing and showed a rapid recovery of ventilation, even after bilateral division of the carotid sinus nerves. Thus, in addition to the demonstration of carotid chemoreceptor activity which was affecting ventilation of these newborn lambs, these experiments suggest that central chemoreceptors are also involved in the regulation of respiration at this critical time.

\section{Summary}

In the rhythmically breathing newborn lamb, division of each carotid sinus nerve resulted in a prompt decrease in ventilation. Within several minutes, all animals showed partial or complete recovery from this effect.

Since nerve division was accomplished by no major changes in the heart rate and blood pressure, the induced fall in ventilation is attributed to interruption of the traffic of potentials between the carotid body and the medullary respiratory center. Thus, respiration is being regulated in part by carotid glomic activity at this time.

\section{References and Notes}

1. Avery, M.E.; Ghernick, V. and Young, M.: Fetal respiratory movements in response to rapid changes of $\mathrm{CO}_{2}$ in carotid artery. J.appl. Physiol. 20: 225 (1965).

2. Biscoe, T.J.: Personal communication.

3. Cross, K.W.: Respiration in the newborn baby. Brit.med. Bull. 17: 160 (1965).

4. Cross, K.W. and Malcolm, J.L.: Evidence of carotid body and sinus activity in newborn and foetal animal. J. Physiol. 118: 10P (1952).

5. Drxon, W.J. and Massex, F.J.: Introduction to statistical analysis, 2nd ed., p. 286 (McGraw-Hill, New York/Toronto/London 1957).

6. Harned, H.S., Jr.; Griffin, Glarence, III; Berryhill, W.S., Jr.; MacKinney, L.G. and SugIokA, K.: Role of carotid chemoreceptors in the initiation of effective breathing of the lamb at term. Pediatrics 39: 329 (1967).

7. Harned, H. S., Jr.; Griffin, G.A., III ; Berryhill, W.S., Jr.; MacKinney, L.G. and Sugroka, K.: Role of hypoxia and $\mathrm{pH}$ decrease in initiation of respiration. Presented to the Symposium de Laesione Foetus Intrauterine Imminenti, Prague, Czechoslovakia, October 1966 (to be published by Excerpta Medica Foundation).

8. Harned, H.S., Jr.; MacKinney, L.G.; Berryhill, W.S., Jr. and Holmes, Garolyn: Effects of hypoxia and acidity on the initiation of breathing in the fetal lamb at term. Amer.J. Dis. Child. 112: 334 (1966).

9. James, L.S. and Adamsons, K., Jr.: Respiratory physiology of the fetus and newborn. New Engl.J. Med. 271: 1352 (1964).

10. James, L.S.; Weisbrot, J.M.; Prince, C.E.; Holaday, D.A. and Apgar, Vrrginia: Acid-base status of human infants in relation to birth asphyxia and onset of respiration. J. Pediat. 52: 379 (1958).

11. Purves, M.J.: Respiratory and circulatory effects of breathing $100 \%$ oxygen in the newborn lamb before and after denervation of the carotid chemoreceptors. J. Physiol. 185: 42 (1966).

12. Purves, M.J.: The effects of hypoxia in the newborn lamb before and after denervation of the carotid chemoreceptors. J. Physiol. Lond. 185: 60 (1966).

13. Purves, M.J. and Biscoe, T.J.: Development of chemoreceptor activity. Brit.med.Bull. 22; 56 (1966).

14. Supported by USPHS Grant HD-00239.

15. Dr. Harned is Senior Investigator of the North Carolina Heart Association.

16. Requests for reprints should be addressed to: Dr. Herbert S. Harned, Jr., Department of Pediatrics, University of North Carolina School of Medicine, Chapel Hill, N. C. 27514 (USA). 